\title{
ALBERT CAMUS NO ENTREMEIO DA AUTORIA MULTILETRADA: RELATO DE EXPERIÊNCIA DIDÁTICO-METODOLÓGICA ${ }^{1}$
}

\author{
Caroline de Morais (UCS / IFRS) \\ Juliene da Silva Marques (UNISUL / IFRS)
}

Resumo: O presente estudo tem como objeto de análise uma prática didático-metodológica aplicada em duas turmas do primeiro ano do Ensino Médio Integrado do IFRS, campus Vacaria. A proposta contou com o estudo da obra $O$ estrangeiro, de Albert Camus, e teve como objetivo romper com a perspectiva do ensino literário tradicional para fazer uso dos multiletramentos literários a fim de desenvolver a autoria estudantil. Para o desenvolvimento do projeto, levaram-se em conta metodologias de ensino que colocassem os estudantes como protagonistas da ação, considerando seu contexto de produção de sentidos, sua bagagem cultural e as linguagens multimidiáticas que costumam utilizar. Desse modo, registram-se, nesta experiência, aportes teóricos direcionados ao ensino da Literatura, bem como embasamentos no que se referem aos letramentos literários, aos multiletramentos e à construção da autoria. Como registro da proposta, usam-se, para análise, mapa conceitual e recortes de enquadramento de vídeos produzidos pelos discentes com base na obra estudada. Diante do fechamento do projeto, constatouse o envolvimento dos participantes para com a atividade, bem como seu desenvolvimento autoral, que fez com que sentidos outros fossem promovidos para a leitura, interpretação e atualização da obra analisada de maneira multimodal.

Palavras-chave: Práticas leitoras; Autoria estudantil; Multiletramentos; $O$ estrangeiro.

\begin{abstract}
This study's main analysis object is a methodological teaching practice conducted in two groups of the first year of High School in the Federal Institute of Technology, Science and Education, campus Vacaria. The proposal was to study the book The Stranger, written by Albert Camus and break the traditional approach to teaching literature, by using multiliteracies and by developing the student's authorship. In order to

1 Título em inglês: "Albert camus and the multiliterate authorship: report of a methodological teaching practice".
\end{abstract}


develop the project, it was taken into account methodologies that allow students to be in the center of the action, considering their context of making meaning, their cultural background and the multimodal languages that they use. Therefore, this experience is based on the theories of literature teaching, literature literacy and multiliteracies as well as the development of authorship. As a record of this proposal, we use, for analysis, conceptual maps and framing clippings of videos made by students based on the books they had studied. By the end of the project, it was found that participants were involved in the activity as well as their authorial development, which made them see other meanings and senses for the reading, interpretation and update of the literary work analyzed in a multimodal manner.

Keywords: Reading practices; Student authorship; Multiliteracies; The Stranger.

\section{INTRODUÇÃo}

$\mathrm{O}$ ato de ler e o contexto escolar necessitam estar em consonância, como propulsores para a formação de opinião dos jovens estudantes. A Literatura, enquanto disciplina, surge no Ensino Médio, sendo imprescindível a presença constante do professor como mediador para a leitura de obras clássicas. O estudioso Antonio Candido (2011, p.176) reconhece a Literatura como "[...] todas as criações de toque poético, ficcional ou dramático em todos os níveis de uma sociedade, em todos os tipos de cultura, desde o que chamamos de folclore, lenda, chiste, até as formas mais complexas e difíceis da produção escrita das grandes civilizações". Com base na amplitude do texto literário, é relevante desenvolver, em sala de aula, diferentes projetos 
que valorizem a leitura; o posicionamento do leitor e a discussão acerca da narrativa. Diante desse panorama, considera-se a obra $O$ Estrangeiro, de Albert Camus, uma ferramenta pertinente para o debate com os adolescentes, que passam por diversos conflitos nessa fase.

O escritor argelino Albert Camus é reconhecido mundialmente por meio da obra $O$ estrangeiro, uma das mais significativas de sua carreira, ao lado de $A$ Peste e $A$ Queda. A obra escolhida para o projeto recebeu adaptações para o cinema e também traduções para diferentes línguas, confirmando a disseminação dessa narrativa. Ganhador do Prêmio Nobel da Literatura em 1957, o escritor é considerado um dos grandes autores no contexto do século XX. Em 1949, por um curto tempo, Albert Camus esteve visitando o Brasil para realizar conferências. Nesse momento, todo o cenário literário manteve a atenção voltada para o autor de $O$ estrangeiro. Em função dessa passagem por solo brasileiro, em 2019, organizaram-se eventos, exposições e menções ao escritor com a finalidade de celebrar os 70 anos da sua visita.

A partir do contexto literário atual e observando a importância do escritor para a formação leitora, optouse por ler e discutir a obra $O$ estrangeiro nas duas turmas de primeiro ano do Ensino Médio Integrado, pertencentes 
ao Instituto Federal do Rio Grande do Sul (IFRS), campus Vacaria. A orientação docente foi realizada pelas autoras do artigo, cada qual em sua respectiva turma, de acordo com um planejamento previamente estabelecido. Assim, a partir dessa perspectiva de ensino, o presente artigo aborda uma experiência didático-metodológica aplicada ao ensino de Literatura, utilizando diversas formas de abordagens e habilidades dos estudantes.

Nesse aspecto, tem-se como problema de pesquisa a seguinte questão norteadora: como o uso dos multiletramentos literários pode promover a autoria estudantil? A partir disso, o objetivo principal é romper com a perspectiva do ensino literário tradicional para fazer uso dos multiletramentos literários a fim de desenvolver a autoria dos discentes. Contam-se, também, com os seguintes objetivos específicos: fomentar a leitura de obras literárias clássicas e utilizar linguagens multimidiáticas no ambiente escolar para a produção autoral a partir de leituras realizadas e do contexto de produção dos discentes envolvidos.

Geralmente, os projetos de leitura são práticas desenvolvidas nas escolas de Ensino Fundamental e Médio, adequando-se ao contexto escolar. Em muitas dessas atividades, há a colaboração de diversas áreas como: 
Filosofia, Sociologia, História, Geografia, entre outras. Essa preocupação em significar a obra literária em diferentes aspectos, torna-a mais próxima do leitor. Nesse âmbito, o presente artigo retrata atividades didático-metodológicas distintas como forma de valorizar a composição da obra literária escolhida, sobressaindo as concepções que Candido (2011p.) reconhece como três faces da função da Literatura:

(1) ela é uma construção de objetos autônomos como estrutura e significado; (2) ela é uma forma de expressão, isto é, manifesta emoções e a visão do mundo dos indivíduos e dos grupos; (3) ela é uma forma de conhecimento, inclusive como incorporação difusa e inconsciente.

(p.178-179)

A organização deste estudo está amparada pela cronologia das intervenções e atividades desempenhadas com o grupo de estudantes, ressaltando os aspectos positivos e negativos de cada ação proposta. Dessa maneira, a prática leitora está permeada constantemente aos aspectos teóricos, que auxiliam na reflexão e avaliação do projeto. Como embasamento teórico, utilizam-se referências no que tange à leitura, aos multiletramentos e à autoria, destacando-se autores como Candido (2011), Rojo (2013) e Orlandi (1998), por fim, a obra de Camus (2018) é referenciada e discutida ao longo do texto. 
Como corpora de análise, utilizam-se materiais produzidos por estudantes, a saber: mapa conceitual e enquadramentos de vídeos. Assim, para atingir os objetivos propostos, temse como base metodológica a abordagem qualitativa e a pesquisa bibliográfica a fim tecer os resultados constatados.

\section{DESENVOLVIMENTO DA AUTORIA A PARTIR DOS MULTILETRAMENTOS LITERÁRIOS: ASPECTOS TEÓRICOS E ANALÍTICOS}

O ensino da Literatura se faz presente em diversos âmbitos do currículo escolar, não estando presente, portanto, apenas na ementa da área de Linguagens, pois contribui significativamente para a construção do conhecimento de diversas áreas, principalmente por fazer ver a perspectiva da humanidade em variados aspectos e tempos. O contato com a Literatura na escola, no entanto, muitas vezes, é visto como algo tradicional, pois, geralmente, limitam-se os títulos e as temáticas de acordo com o que se pretende em relação ao conteúdo. Dessa maneira, é um desafio fazer com que todos os estudantes, em seus aspectos diversos, interessemse pela mesma obra em uma mesma temporalidade.

Além disso, a abordagem clássica da Literatura vem passando por diversas mudanças a fim de se adaptar aos novos contextos de recepção. Essas alterações se dão em relação ao uso de obras como pretextos para ensino de 
Escolas Literárias e aspectos gramaticais, somente. Ou, até mesmo, as abordagens referentes à perspectiva do autor, que não consideram, em vários casos, a questão da recepção leitora, que se faz diversa e, portanto, sem limitação.

De acordo, então, com a abordagem clássica dos estudos literários, todos deveriam chegar a uma mesma resposta, mesmo possuindo concepções de mundo e de vida diferentes. É por isso que Alves (2013) faz a seguinte explicação:

É fundamental pensar procedimentos que fujam da tradicional aula expositiva de literatura, das abordagens que têm como ponto de partida não o texto, mas informações históricas, formais, temáticas sobre autores e obras. É imprescindível sempre partir do texto literário - seja ele popular ou erudito - e procurar, no âmbito da escola, realizar o que Colomer (2007) ${ }^{2}$ chama de leitura compartilhada. Noutras palavras, estimular o jovem leitor ou a criança a se pronunciar sobre o texto, a dizer seu ponto de vista, a dialogar com o texto e com os colegas. (p.45)

Esse modelo tradicional de ensino está sendo, aos poucos, substituído por uma concepção contemporânea de tratamento literário, considerando, nessa perspectiva, não apenas a decodificação, mas a interpretação e a reinvenção do texto. Isso porque, considera-se, de acordo com Aguiar

2 COLOMER, Teresa. Andar entre livros: a leitura literária na escola. Laura Sandroni (Trad.). São Paulo: Global, 2007. 
(2013, p.153), que “[...] o processo de leitura pressupõe, portanto, a participação ativa do leitor, que não é mero receptor de uma mensagem acabada, mas, ao contrário, interfere na construção dos sentidos, preenchendo os vazios textuais de acordo com sua experiência de leitura de vida". Diante disso, o estudante precisa ter voz ativa nas práticas leitoras, fazendo com que suas experiências e bagagem de vida dialoguem com o texto lido, bem como com a leitura dos demais colegas.

Nesse contexto, a recepção leitora é trabalhada a partir do letramento literário, pois o que entra em jogo não é apenas o que foi lido ou a forma como os sujeitos receberam a obra em uma determinada época, tendo em vista que o letramento literário pressupõe que o leitor dialogará com a obra diante de seu tempo e de seu espaço, realizando, assim, uma atualização a respeito da materialidade trabalhada. Isso porque, para Ferrazi Júnior e Carvalho (2017, p.89), “[...] o sentido não está no texto; ele é construído pelo leitor, que vai estabelecendo relações entre a informação textual (presente no que se lê), o seu conhecimento de mundo e as outras leituras já realizadas".

É importante destacar que, para Paulino e Cosson (2009), o letramento literário não começa e nem termina no espaço 
escolar, pois ele está conectado com a vida desse sujeito que atribui sentidos a obras variadas, em suas múltiplas formas, ao longo de sua vida. A partir disso, vê-se, portanto, esse modo de leitura não apenas como um objetivo, mas como um processo, que se dá permanentemente na interação entre leitor e obra lida, que se renova a cada leitura realizada.

É diante desse ponto de vista que Dalvi (2013, p.89 - grifo da autora) considera que "[...] é necessário, sempre que possível, 'atualizar' o texto literário, entendendo que não há compreensão original ou sentido único a ser atingido. Todo texto pede para ser reinventado". Com isso, observase a visão dialógica que é necessária para com o texto lido, levando em conta todos os aspectos da construção de sentidos, principalmente o protagonista que se coloca em cena: o leitor.

Também é relevante salientar que não se atua, no ambiente escolar, com leitores já consolidados e inseridos no mundo literário, seja clássico ou popular. Desse modo, a imersão para com o mundo da leitura é um processo que precisa ser valorizado e construído de modo participativo em relação aos estudantes, levando em conta o seu modo de ver o mundo. Em função disso, é importante considerar o contexto atual de produção e de recepção de textos, que 
está, cada vez mais, fluido e dinâmico, sendo parte, assim, da vida da maioria dos estudantes. Para Zacharias (2016):

Ultimamente, a participação na cultura letrada passou a ser mediada por vários dispositivos e por outras maneiras de ler que desafiam as concepções de leitura mais tradicionais. O aparecimento de formas de comunicação como as redes sociais (a exemplo do WhatsApp e do Facebook) implica transformações no processo de criação e de recepção de textos, uma vez que exploram aspectos como a multimodalidade, a hipertextualidade e a interatividade. Estas formas de interação demandam habilidades de leitura e de produção específicas e, consequentemente, exigem uma formação mais específica dos integrantes. (p.20)

Em razão dessa perspectiva, faz-se ver as mudanças que implicam a metodologia ensino-aprendizagem. A respeito das propostas que fazem sentido para os estudantes e, portanto, apliquem-se à realidade desses mesmos sujeitos, é necessário vincular-se ao ambiente de produção de sentidos ao qual estão inseridos, que, muitas vezes, dizem respeito aos meios virtuais e formas de produção multimidiáticas.

Diante disso, associa-se, portanto, o letramento literário aos multiletramentos, que, para Rojo (2013):

Busca justamente apontar, já de saída, por meio do prefixo "multi"', para dois tipos de "múltiplos" que as práticas de letramento contemporâneas envolvem: por um lado, 
a multiplicidade de linguagens, semioses e mídias envolvidas na criação de significação para os textos multimodais contemporâneos e, por outro, a pluralidade e a diversidade cultural trazidas pelos autores/leitores contemporâneos a essa criação de significação. (p.14 - grifos da autora)

A partir disso, então, ter-se-iam os multiletramentos literários, que exploram não apenas a multiculturalidade, já valorizada pela Literatura, mas também, a multimodalidade, que faz com que as diferentes mídias e recursos digitais entrem em cena para corroborar a construção de sentidos no entremeio da realidade dos estudantes. Vale mencionar que, para Braga (2010), os recursos digitais e as unidades de informação de naturezas diversas, considerando som, movimento, imagem etc., fazem com que seja construída uma nova forma de recepção leitora, que ultrapassa as formas de interpretação dos gêneros multimodais tradicionais.

No que tange à multimodalidade, não é restrita ao ambiente digital ou ao contexto contemporâneo, pois ela diz respeito ao uso de diferentes recursos comunicativos. Desse modo, pode-se perceber, por exemplo, em uma contação de histórias infantil, em que há texto, imagem, leitura etc., enfim, características da multimodalidade.

Perante esse contexto, consideram-se, também, os aspectos autorais que são possibilitados pelos 
multiletramentos literários, pois, para Pêcheux (2014, p.59), o ato de interpretar já seria uma escritura, por possibilitar ao sujeito um deslocamento, um fazer sentido outro que não o instituído. Ou seja, não se lida apenas com a decodificação, com perguntas tais qual "o que o autor quis dizer?", mas com aspectos da criação a partir de associação com sentidos outros vivenciados pelo próprio sujeito escolar.

Essa autoria diz respeito à polissemia que pode ser desenvolvida no ato da leitura, a partir de ações de interpretação que não se restringem à paráfrase. Isso porque, quando há apenas repetição de sentidos, isto é, todos com as mesmas respostas, configura-se o movimento parafrástico em que o mesmo ocorre continuadamente. Já quando há um deslocamento, em outras palavras, sentidos outros que surgem para fazer significar de modo diferente, constitui-se, assim, o movimento polissêmico, que possibilita a autoria (ORLANDI, 1998).

É, então, a partir dessa consideração no que se refere aos multiletramentos literários que se deu a prática didáticometodológica aqui descrita. Além dos aspectos teóricos direcionados à obra de Camus (2018), foi possibilitado, aos estudantes, a interpretação - que é escritura para Pêcheux e a configuração da autoria por meio da produção de diversas 
materialidades multimodais a respeito da obra, como forma de atualização em relação ao tempo e ao espaço.

As atividades desenvolvidas em sala de aula buscaram a integração entre os estudantes e o contexto abordado na obra literária. Nesse aspecto, a leitura e as diferentes percepções leitoras contribuíram para a discussão entre os estudantes, dando destaque a variados momentos da narrativa a partir da visão de mundo de cada um. Segundo Candido (2011), o acesso à Arte e à Literatura são elementos básicos para a formação do indivíduo, compreendidos como fatores essenciais. Isso porque a Literatura contribui para o conhecimento do mundo e também para o autoconhecimento do próprio sujeito.

Para o desenvolvimento das atividades planejadas, a primeira ação envolvendo o grupo de estudantes foi a apresentação da obra $O$ estrangeiro. Nesse primeiro contato, com a apresentação realizada pelas docentes, os leitores receberam dicas para a leitura, como realizar anotações; destinar um tempo suficiente para a leitura de, no mínimo, um capítulo integralmente, não fazendo leituras fragmentadas; combinar uma leitura conjunta com algum colega a fim de discutirem os acontecimentos e trocarem ideias acerca do enredo. Desse modo, a recepção leitora é 
constituída a partir da produção de opinião e da construção de conhecimento literário.

Em data combinada previamente, o grupo de estudantes em conjunto com as professoras realizaram uma discussão sobre a obra literária, os aspectos gerais, e sobre as personagens principais. Nesse momento, construíramse características e posicionamentos, tendo como ponto de partida as ações desempenhadas pelas personagens Meursault, Raymond, Marie e Salamano. Abes (2018), em estudo sobre a obra, ressalta a importância do leitor na função de preencher as lacunas para acompanhar a trama da narrativa, considerando que essa atividade potencializa o texto literário.

Essa oportunidade de falar acerca da obra lida, de ouvir considerações observadas pelos colegas, de reconstruir a narrativa de modo mais concreto, torna-se eficaz na leitura geral da obra literária, sanando dúvidas ou questionamentos que tenham permanecido após a leitura individualizada. Essas interações proporcionadas pela obra literária 0 estrangeiro, oportunizaram a apropriação e a reflexão do leitor, pois possibilitaram o diálogo com a obra e com os colegas. Conforme Candido (2011):

A literatura tem sido um instrumento poderoso de instrução e educação, entrando 
nos currículos, sendo proposta a cada um como equipamento intelectual e afetivo. [...]. A literatura confirma e nega, propõe e denuncia, apoia e combate, fornecendo a possibilidade de vivermos dialeticamente os problemas. [...]. (p.177)

A partir das considerações realizadas, no encontro seguinte, as turmas de Ensino Médio Integrado foram separadas em pequenos grupos para desempenhar novas atividades voltadas ao livro selecionado. A escolha dos integrantes de cada grupo ficou sob a responsabilidade dos próprios estudantes, reconhecendo que as atividades desenvolvidas em grupos precisam de uma afinidade entre os envolvidos. Os grupos compreendiam entre 3 e 4 componentes, adequando-se ao número de estudantes e aos capítulos divididos em função do número de páginas, sendo uma divisão equivalente para cada grupo. A determinação dos capítulos foi realizada por meio de sorteio, no qual um integrante acompanhou, demonstrando imparcialidade na escolha.

Após esse primeiro contato com a obra e com a divisão dos grupos, cada estudante, de modo individual, teve a tarefa de realizar uma nova leitura do capítulo sorteado. Nesse sentido, durante um período de aula, todos os estudantes refizeram a leitura específica do capítulo, com o qual desempenhariam 
novas atividades. Durante esse momento de leitura, cada um tinha a orientação de realizar anotações acerca dos fatos mais relevantes presentes no capítulo, para que, no próximo passo, em conjunto com o seu grupo, pudessem discutir e aprofundar as situações diagnosticadas.

A maioria dos estudantes respeitou o momento de silêncio e de leitura intensificada, demonstrando comprometimento com as ações em torno do ato de ler. É significativo considerar que o discente, na posição de leitor, credita valor à obra literária. Manguel (1997) sustenta que o ato de ler é uma função essencial, quando diz que:

Em cada caso é o leitor que lê o sentido; é o leitor que confere a um objeto, lugar ou acontecimento uma certa legibilidade possível, ou que a reconhece neles; é o leitor que deve atribuir significados a um sistema de signos e depois decifrá-lo. Todos lemos a nós e ao mundo à nossa volta para vislumbrar o que somos e onde estamos. Lemos para compreender, ou para começar a compreender. Não podemos deixar de ler. Ler, quase como respirar, é nossa função essencial. (p.19-20)

Em seguida, reunidos com os colegas, ocorreu a comparação das anotações e a discussão acerca do que realmente era relevante para a construção da narrativa, expondo os significados construídos por meio da leitura. 
Essa oportunidade de debate e construção de sentidos aprimorou e aproximou o capítulo dos estudantes, levandoos a uma reflexão mais ponderada acerca da obra literária.

No encontro seguinte, separados nos grupos pré-definidos em momento anterior, os estudantes foram orientados a unir todas as anotações realizadas sobre o capítulo e construírem um mapa conceitual com os elementos mais importantes. Nessa situação, a maioria dos grupos obteve sucesso e facilidade, pois eles já haviam discutido acerca dos acontecimentos mais relevantes. Para Candido (2011, p.182), as produções e obras literárias "[...] de todos os tipos e todos os níveis, satisfazem necessidades básicas do ser humano [...]", logo, essa aproximação e facilidade se devem ao contexto de empatia com a obra discutida. Então, nessa ocasião, eles puderam definir a melhor forma de apresentar o capítulo, tornando-o compreensível e esteticamente agradável. Para essa tarefa, muitos grupos utilizaram-se de cores e formatos diferenciados para construir o mapa conceitual. Os discentes ficaram satisfeitos com a construção dos mapas conceituais, evidenciando a capacidade de produção em grupo. 


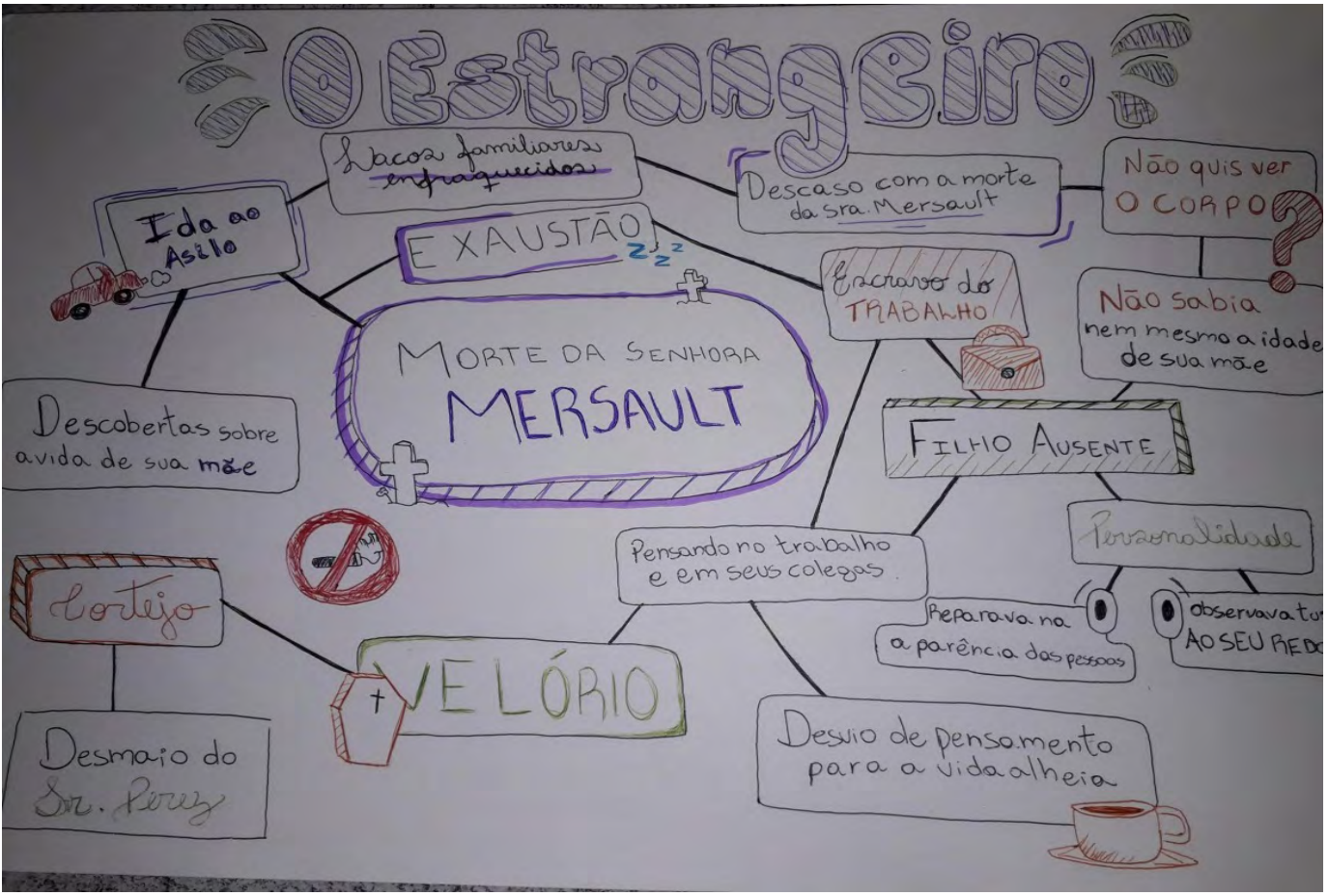

Figura 1 - Mapa conceitual

Fonte: Arquivo da pesquisa, 2019.

A partir da discussão em grupo, então, os estudantes puderam traçar as palavras-chave e as principais questões referentes ao capítulo lido, fazendo conexões que evidenciassem a sua forma de interpretação do texto. Com a produção do mapa, além das associações das partes, exigindo inferências leitoras, também se obteve a atenção para o uso dos recursos linguísticos a fim da confecção desse gênero textual. Podem-se destacar, na figura 1, o uso variado de tamanho de letras para determinadas palavras, o formato 
diverso dos balões com os termos destacados, além da utilização de cores e de desenhos que representam o enredo em questão: a morte da mãe de Meursault. Perante essa produção, os estudantes não se limitaram ao que o autor disse, apenas em um aspecto parafrástico, mas construíram sentidos e conectaram informações outras para chegarem ao resultado pretendido em acordo mútuo entre as diversas leituras realizadas, ou seja, em um movimento polissêmico.

$\mathrm{Na}$ aula seguinte, os grupos, por ordem dos capítulos, fizeram a exposição e apresentação dos mapas conceituais construídos na aula anterior, explorando, assim, o uso da oralidade como mais uma modalidade textual. Em função disso, toda a turma teve a oportunidade de reconstruir a narrativa por meio da sequência de mapas conceituais. Enquanto os grupos iam apresentando, alguns estudantes realizavam anotações, reconstruindo, novamente, a narrativa. Essa ação demonstra que há uma incessante estruturação da mesma leitura, isto é, há uma construção de novos sentidos a partir de novas leituras, tendo em vista as mudanças que ocorrem na perspectiva desses sujeitos.

Vale mencionar que os discentes, além da explicação sobre o que ocorreu em cada capítulo, fizeram movimentos de interpretação que se direcionaram às associações com 
materialidades diversas externas à obra, bem como com as conflitos vivenciados na contemporaneidade. Isto é, procuraram, por meio da oralidade, fazer novas conexões a fim de atualizar a obra de Camus (2018) para o contexto atual em que vivem. Após o último grupo, as professoras realizaram o fechamento da atividade, salientando que a obra literária ganhou novo formato ao conceber a sequência por intermédio dos mapas conceituais, oportunizando um contexto polissêmico de leitura.

Chartier (2001) contribui significativamente ao reconhecer que $\mathrm{o}$ ato de ler individualizado é uma prática articulada ao considerar que o leitor, ao final de sua leitura, não será o mesmo que era no início. Em função desse aspecto, salientase o quanto a leitura é transformadora, sendo que ocorre um envolvimento com os elementos internos da narrativa, como as personagens e as situações abordadas. Logo, o leitor será modificado ao repensar e ao reviver o contexto que a obra literária apresenta. Em se tratando de $O$ estrangeiro, muitos fatores e questionamentos são motivos de reflexões e posicionamentos por parte dos jovens estudantes.

A última atividade elaborada pelo grupo discente foi a construção de um vídeo representando um momento do capítulo sorteado. A escolha do trecho ficou a critério do 
grupo, dando oportunidade para representar a circunstância que achassem mais conveniente. Para a proposta, os estudantes deveriam montar o cenário e as personagens por meio de desenhos ou de recortes de revistas e jornais, aproximando-se de uma animação. Outra opção foi o uso de aplicativos próprios de animação, ficando a critério de cada grupo a escolha do recurso utilizado. Alguns vídeos foram apresentados para as turmas a título de exemplo. Todas as ações foram construídas no ambiente escolar, nos momentos de aula de Língua Portuguesa com a supervisão das docentes mediadoras. Para a organização do vídeo, todos os grupos deveriam construir um roteiro como forma de facilitar a gravação. O audiovisual foi gravado pela câmera do celular ou por aplicativos de edição de vídeos, também com o uso do celular. O duração da produção deveria compreender entre 1 e 3 minutos, de modo a não se tornar cansativa.

O trabalho finalizado foi compartilhado com as docentes ao final da aula. Apenas um grupo não atingiu o tempo mínimo proposto, e dois entregaram o material final com atraso. A maioria dos estudantes demonstrou interesse e empenho na produção do audiovisual. Para o encerramento das atividades acerca da obra literária de Camus (2018), a turma teve um período de aula para apreciar a produção dos colegas. Então, 
todos assistiram aos vídeos produzidos, seguindo a ordem da narrativa e, mais uma vez, reconstruíram-na e observaram um novo formato da mesma leitura inicial do livro impresso.

Para a atividade audiovisual cabe destacar a preocupação dos estudantes em serem fiéis ao que estava posto na narrativa. Nesse sentido, muitos tiveram atenção com o tom de voz para adequar ao que estava sendo retratado, aos sons externos necessários para montar o contexto, além de caracterizar as personagens adequando-as ao que a narrativa apresentava. Com isso, a tarefa proposta confirma uma leitura mais detalhada e atenciosa de $O$ estrangeiro como um todo, e não apenas a leitura do capítulo destinado ao grupo.
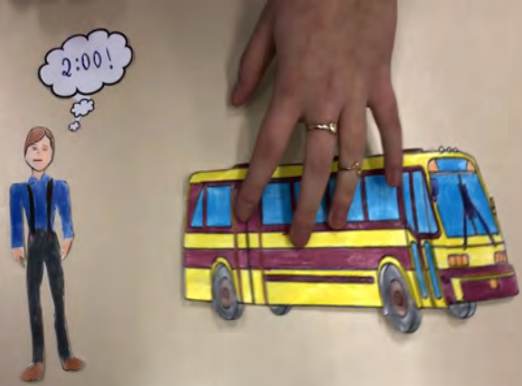

Figura 2 - Vídeo 1

Fonte: Arquivo da pesquisa, 2019.

No trecho de vídeo acima (figura 2), observam-se os momentos iniciais da narrativa, em que Meursault se organiza para ir ao asilo em Marengo devido ao comunicado do falecimento de sua mãe. A primeira imagem registra o 
momento em que ele está pronto para embarcar no ônibus: "Peguei o ônibus às duas horas. Fazia muito calor" (CAMUS, 2018, p.13). Em seguida, os estudantes evidenciaram os principais diálogos que Meursault teve no asilo e no velório, bem como registraram o cortejo fúnebre, dando destaque para a insensibilidade da personagem. Conforme a seguinte passagem:

O sol derretera o asfalto. Os pés enterravamse nele, deixando aberta sua polpa luzidia. Por cima do carro, o chapéu do cocheiro, de couro curtido, parecida ter sido moldado nesta lama negra. Eu estava um pouco perdido entre o céu azul e branco e a monotonia destas cores, negro pegajoso do asfalto aberto, negro desbotado das roupas, negro laca do carro. Tudo isto, o sol, o cheiro do couro e de esterco do carro, o do verniz e do incenso, o cansaço de uma noite de insônia, me perturbava o olhar e as ideias. (CAMUS, 2018, p.25)

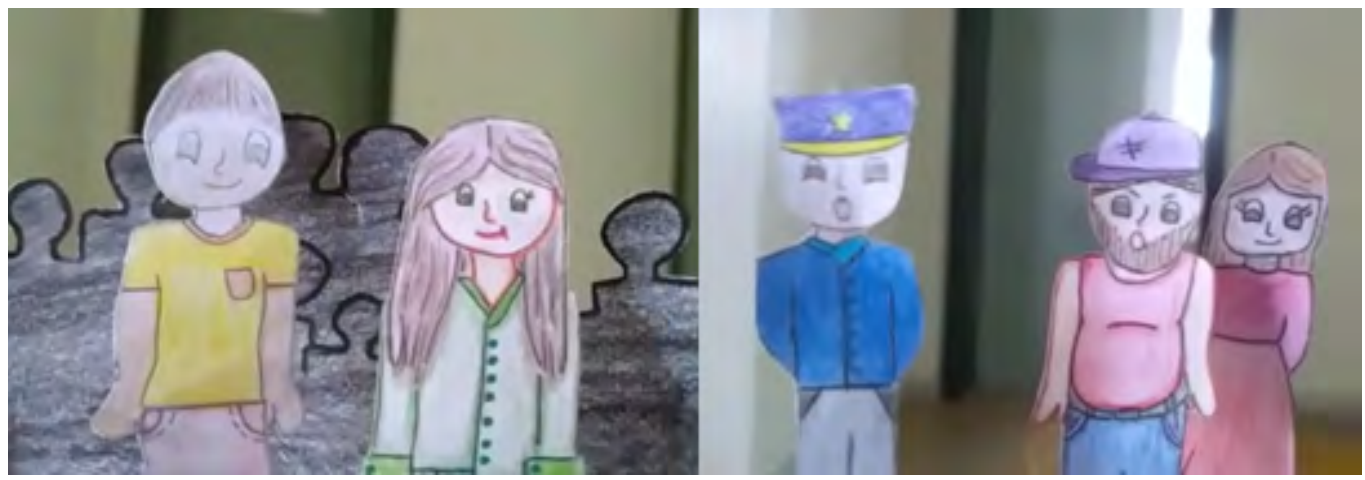

Figura 3 - Vídeo 2

Fonte: Arquivo da pesquisa, 2019. 
O trecho do vídeo acima (figura 3) retrata o momento em que Raymond agride uma moça em seu quarto. Diante desse acontecimento, uma multidão se junta para ver o que está acontecendo, incluindo Meursault e Marie, conforme a passagem: "[...] Uns ruídos surdos e a mulher berrou, mas de maneira tão horrível que o corredor se encheu logo de gente. Marie e eu também saímos. A mulher continuava a gritar e Raymond não parava de bater [...]" (CAMUS, 2018, p.42-43). Em seguida, chega o guarda para ajudar no desfecho da situação e acabar com a cena de violência. Por meio dos desenhos, observa-se que a tarefa foi construída com extremo cuidado, em consonância com a narrativa e o tema abordado.

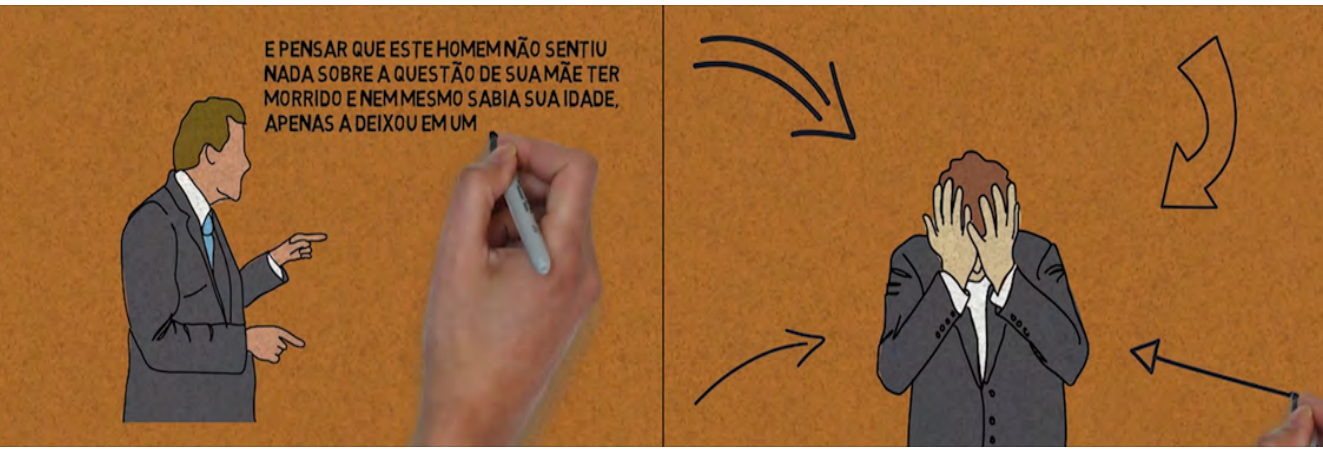

Figura 4 - Vídeo 3

Fonte: Arquivo da pesquisa, 2019.

A figura 4 aborda o contexto do julgamento final, sendo considerado um dos pontos mais relevantes da obra. Nesse momento, Meursault deveria ser julgado pelo crime 
que cometeu, entretanto, um fato se coloca em dúvida: a personagem estava sendo julgada pelo assassinato cometido contra o árabe ou pela insensibilidade diante da morte de sua mãe? O então réu retoma os fatos mencionados pelo promotor:

Resumiu os fatos a partir da morte de mamãe. Relembrou minha insensibilidade, o meu desconhecimento da idade dela, o meu banho de mar do dia seguinte, com uma mulher, o cinema, Fernandel, e por fim a volta com Marie. [...] Chegou em seguida à história de Raymond. Achei que à sua maneira de ver os acontecimentos não faltava clareza. O que dizia era plausível. (CAMUS, 2019, p.104)

A escolha dos trechos dos capítulos determinam os acontecimentos mais marcantes para os discentes, posto que cada grupo poderia selecionar qualquer momento para gravar. Além disso, com o uso de recursos linguísticos variados, os estudantes puderam recriar a narrativa por meio de sua própria perspectiva de construção. Desse modo, cada grupo usou o que julgou mais significativo para retratar a cena/passagem escolhida. Com isso, observou-se nas diversas produções a utilização de múltiplos recursos, a título de exemplo: a movimentação dos desenhos em um lugar plano, auxiliando no decorrer da narrativa (figura 2); o uso de cenário externo real, como a porta ao fundo (figura 3); 
a confecção de desenhos das personagens fixados em palitos ou canetas, como fantoches (figura 3); e alguns estudantes optaram pelo uso de aplicativo (figura 4). É importante destacar que, mesmo diante de materialidades diferentes, os estudantes deram voz às personagens mediante sua própria leitura, dividindo-se em relação à dramatização sonora conforme as personagens, dando destaque para a valorização da oralidade.

Em função da participação do grupo discente foi possível verificar o uso de várias mídias para a construção de leituras próprias da narrativa de Camus (2018). Nesse sentido, a obra $O$ estrangeiro, que é considerada um clássico da Literatura Universal, teve uma reconstrução de maneira atual e tecnológica, casando o tradicional com o moderno a partir da autoria dos próprios estudantes. Portanto, é possível desenvolver atividades diferenciadas no ambiente escolar envolvendo os multiletramentos literários e desenvolvendo a autoria discente, por meio da integração entre a obra e o jovem, com mediação do professor.

\section{CONSIDERAÇÕES FINAIS}

A partir do que foi discutido e da experiência didáticometodológica vivenciada, constatou-se a relevância de novas práticas para o ensino de Literatura. As professoras 
envolvidas no projeto puderam prestigiar o envolvimento dos estudantes para com a obra literária selecionada. Essas ações rompem com a visão tradicional de leitura como objeto de avaliação em prova escrita. Por meio desse projeto, observou-se que o momento, também avaliativo, possibilitou uma nova aprendizagem ao viver a narrativa e interpretá-la mediante o próprio olhar e as formas de viver o mundo, que se dão, em grande parte, de modo digital.

Candido (2011) reconhece que a leitura e a arte são elementos básicos para o cidadão, independente da sua condição social. De acordo com o estudioso, a produção literária tem uma função humanizadora, modificando o leitor. Em função disso, também se observou o modo como os estudantes representaram e leram os conflitos humanos, que se dão, em diferentes escalas, na vida de cada sujeito. Puderam, por meio da leitura e da produção de textos multimodais, viver a experiência de Meursault e compará-la a diversas outras frustrações que fazem parte da humanidade.

A produção de mapas conceituais e a gravação de vídeos exigiram dos discentes, além da leitura da obra de Camus (2018), a organização dos fatos e a convivência em grupo. Durante a execução das tarefas, a troca de experiências e as constantes discussões acerca da narrativa tornaram 
o projeto favorável para o aprendizado da Literatura. Ao perceber que as atividades estavam todas vinculadas, os jovens reconheceram as inúmeras possibilidades de autoria, despertando vertentes pouco exploradas no ambiente escolar.

A significação da obra literária para os discentes envolvidos foi sendo modificada a cada procedimento realizado. Da mesma forma, que as discussões tornaram-se mais fundamentadas com as diversas leituras e intervenções da mesma narrativa. Nesse âmbito, a Literatura conquista espaço no ambiente escolar e na vida do estudante, sendo retratada, também, no contexto nacional em alusão aos 70 anos da visita do autor ao Brasil. Com o presente projeto didático-metodológico, o corpo discente do IFRS, campus Vacaria, sentiu e vivenciou os dramas e os conflitos gerados pela obra $O$ estrangeiro.

$\mathrm{Na}$ busca por fazer com que o ensino se aproxime da realidade dos estudantes, principalmente, por meio de recursos linguísticos multimodais, promoveu-se os multiletramentos literários. Com a aplicação do projeto, foi constatado o envolvimento de todos os sujeitos na execução, fazendo com que os momentos compartilhados fossem mais que conteúdos, mas sim, oportunidades de crescimento 
pessoal e acadêmico. A cada nova tarefa solicitada ocorriam releitura e novas discussões, gerando uma atuação engajada. Logo, em projetos futuros que se pretendem realizar por meio da perspectiva multimidiática, os discentes estarão mais animados com a sua própria autoria acerca da obra literária.

\section{REFERÊNCIAS}

ABES, Gilles Jean (2018). "Traduzir O estrangeiro, de Albert Camus: pensar a luz estrangeira na literatura em prosa". Remate de Males, CampinasSP, 38(2), 683-702. In https://periodicos.sbu.unicamp.br/ojs/index.php/ remate/article/view/8652369/18889 Acesso em 9.Set.2019.

AGUIAR, Vera Teixeira (2013). "O saldo da leitura". In: DALVI, Maria Amélia; REZENDE, Neide Luzia de; JOVER-FALEIROS, Rita (Orgs.). Leitura de literatura na escola. São Paulo: Parábola.

ALVES, José Hélder Pinheiro (2013). "O que ler? Por quê? A literatura e seu ensino". In: DALVI, Maria Amélia; REZENDE, Neide Luzia de; JOVERFALEIROS, Rita (Orgs.). Leitura de literatura na escola. São Paulo: Parábola. BRAGA, Denise Bértoli (2010). "A comunicação interativa em ambiente hipermídia: as vantagens da hipermodalidade para o aprendizado no meio digital". In: MARCUSCHI, Luiz Antônio; XAVIER, Antonio Carlos (Orgs.). Hipertexto e gêneros digitais: novas formas de construção de sentido. 3.ed. São Paulo: Cortez.

CAMUS, Albert (2018). O Estrangeiro. 44.ed. Rio de Janeiro: Record. CANDIDO, Antonio (2011). Vários escritos. Rio de Janeiro: Ouro sobre azul. CHARTIER, Roger (2001). Práticas da leitura. São Paulo: Estação Liberdade. DALVI, Maria Amélia (2013). "Literatura na escola: propostas didáticometodológicas". In: DALVI, Maria Amélia; REZENDE, Neide Luzia de; JOVER-FALEIROS, Rita (Orgs.). Leitura de literatura na escola. São Paulo: Parábola. 
FERRAZI JÚNIOR, Celso; CARVALHO, Robson S. de (2017). De alunos a leitores: o ensino da leitura na Educação Básica. São Paulo: Parábola. MANGUEL, Alberto (1997). Uma história de leitura. São Paulo: Companhia das Letras.

ORLANDI, Eni Pulcinelli (1998). "Paráfrase e polissemia: a fluidez nos limites do simbólico". Rua, Campinas, (4), 9-19. In https://periodicos.sbu. unicamp.br/ojs/index.php/rua/article/view/8640626/8177 Acesso em 14.Set.2019.

PAULINO, Graça; COSSON, Rildo (2009). "Letramento literário: para viver a literatura dentro e fora da escola". In: ZILBERMAN, R.; RÖSING (Orgs.). Escola e leitura: velha crise, novas alternativas. São Paulo: Global.

PÊCHEUX, Michel (2014). "Ler o arquivo hoje". In: ORLANDI, Eni Puccinelli (Org.). Gestos de leitura: da história no discurso. Campinas, SP: Unicamp. ROJO Roxane (2013). "Gêneros discursivos do círculo de Bakhtin e multiletramentos". In: ROJO, Roxane (Org.) Escol@ conectada: os multiletramentos e as TICs. São Paulo: Parábola.

ZACHARIAS, Valéria Ribeiro de Castro (2016). "Letramento digital: desafios e possibilidades para o ensino". In: COSCARELLI, Carla Viana (Org.). Tecnologias para aprender. São Paulo: Parábola.

Caroline de Morais é Doutoranda em Letras pelo Programa de Doutorado em Letras (UCS). Bolsista CAPES. Docente do Ensino Básico Técnico e Tecnológico no IFRS, campus Vacaria. É autora de artigos como Literatura Midiática: livro trailer de Triste fim de Policarpo Quaresma (Revista Trama); Diálogo Literário: uma perspectiva freireana (Revista Estação Literária); entre outras publicações. Participa do grupo de pesquisa "Mediação de leitura literária: análise de instâncias paratextuais em obras selecionadas pelo PNBE" (UCS), sob coordenação da Profa Drạ- Flávia Brocchetto Ramos. E-mail:cacarolpf@yahoo.com.br ORCID iD: https://orcid.org/0000-0002-6888-1516

Juliene da Silva Marques é Doutoranda em Ciências da Linguagem pelo Programa de Pós-graduação em Ciências da Linguagem (Unisul). Bolsista 
CAPES. Docente do Ensino Básico Técnico e Tecnológico no IFRS, campus Vacaria. É autora de artigos como Espelhamento (in)comum: um olhar discursivo sobre a propaganda da Base Nacional Comum Curricular (Revista Caderno de Letras - UFF); A im(p)unidade parlamentar: ditadura e memória (Memorare - Unisul); entre outras publicações. É membro dos grupos de pesquisa "Relações de Poder: esquecimento e memória" (Grepem - Unisul) e "Ensino e aprendizagem interdisciplinar" (GPEI IFSC).

E-mail:juliene.marques@hotmail.com

ORCID iD: https://orcid.org/0000-0001-5347-8815

Recebido em 25 de setembro de 2019. Aprovado em 16 de agosto de 2020. 